\title{
Session 4: The Impact of HIV/AIDS on Education and the Teaching Profession, II
}

The session was chaired by Ms Samidha Garg, who introduced Ms Lucy Barimbui, EFAIDS Co-ordinator of the Kenya National Union of Teachers (KNUT), and Dr Paul Miller.

Ms Barimbui presented her research, entitled 'Education for All and the HIV/AIDS Pandemic in Kenya', saying that the first case of HIV/AIDS in Kenya was identified in 1984. Since then, the negative impact of the pandemic had been felt in all sectors - 'in our homes, education offices, schools and colleges'. However, inroads had been made into the epidemic, as the most recent prevalence rate was estimated at 5.1 per cent, a fall from 5.9 per cent in 2005 and a sharp decline from the 14 per cent estimated in 2000 . It was estimated that the number of new cases among adults was falling dramatically, but the number of deaths had risen to an estimated 150,000 a year, and 1.3 million adults and 100,000 children were HIV-positive.

Prevalence rates varied across provinces: Nyanza had the highest rate at 13.1 per cent, the rate in Nairobi was 9 per cent, the Coast 6 per cent and North Eastern Province only 1 per cent. One of the major concerns was the number of orphaned children and the increase in child-headed households. Poverty was on the increase, with the loss of family breadwinners and sick employees leading to reduced productivity in the workplace. All this was made worse by the loss of skilled manpower due to sickness and death. The need to replace this human capital had led to a high level of demand for training and additional human resources. There was also a need for assistance with medical costs.

Ms Barimbui said that since December 1999, when the pandemic was first declared a national disaster, the Kenyan Government had taken some measures. By 2003 a national council had been put in place to co-ordinate HIV/AIDS initiatives and in 2005 the President launched the Total War Against AIDS (TOWA)

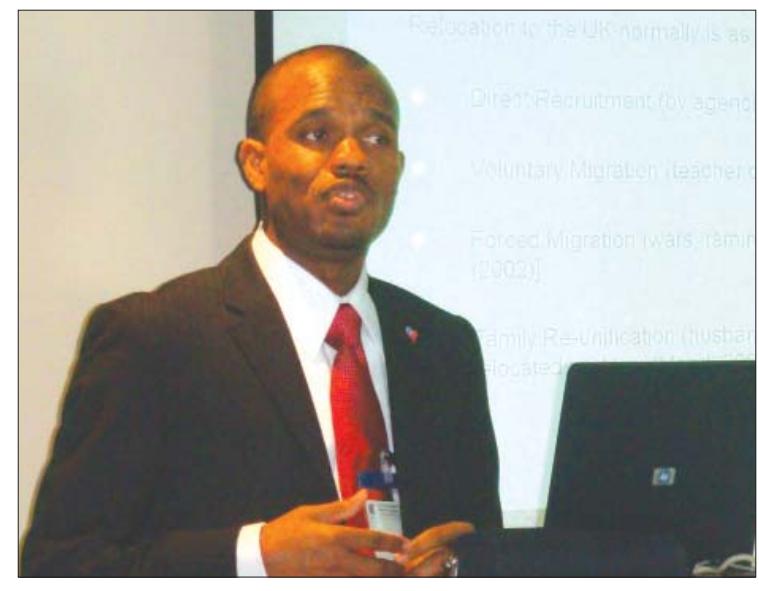

Dr Paul Miller

programme. A multi-sectoral approach was adopted and the Ministry of Education led the public sector in taking action through resource mobilisation and policy implementation. The teaching profession, which had remained 240,000-strong for the last five years, included an estimated 10,000 teachers who were HIVpositive; 3,000 of these had gone public and participate in the support group 'Teachers with AIDS'. Despite openness on the part of some teachers, many were still uncomfortable about benefiting from VCT. To make matters worse, IMF and World Bank strictures on the public sector wage bill had caused teacher recruitment to remain static for the last five years.

In the Kenyan education system, the impact and effect of HIV/AIDS had a deleterious effect overall on education quality. Ms Barimbui said there were high levels of absenteeism among learners, and those students who did attend school often displayed anxiety, confusion and insecurity. The number of orphans and vulnerable children had risen to around 2 million and the level of enrolment and completion rates among learners had fallen. Ms Barimbui reported that it had proved difficult to cover the school syllabus in many subject areas and there is a perception that high mortality levels exist among teachers. A growing number of families were breaking up as the infected and affected were subject 
to stigma and discrimination within their own communities and families. Among teachers specifically, it was estimated that death rates were sometimes as high as six per day. Many teachers appeared ill-prepared to undertake the role of counsellors and they were also obliged to carry the burden of being caregivers and community leaders. Many were frequently obliged to officiate at the funerals of AIDS victims.

Realising that HIV/AIDS was reversing gains which had been made nationally towards the achievement of EFA goals, the Kenyan Project commenced with KNUT's decision to make a positive contribution to the situation created by the HIV/AIDS pandemic. Despite a lack of data and resources, and a low level of awareness about HIV/AIDS among teachers, the 200,000 strong membership of KNUT, with the support of El, the American Federation of Teachers, UNESCO, USAID, the Ministry of Education and the Kenyan Teaching Service Commission, has embarked on a programme of HIV education. The intention is to build the capacity of the union to help mitigate the results of the HIV/AIDS pandemic. An intensive advocacy programme involving 10,000 teachers has been launched with user-friendly HIV/AIDS workplace programmes. Materials on HIV/AIDS have been published and widely disseminated, including materials which focus on the reduction of stigma and discrimination. Posters, flyers, murals, poems and songs have been distributed among learners. These activities have empowered teachers to become involved in breaking the silence and participating in education about HIV/AIDS. Links with service providers have been created to enable teachers who wish to access VCT to do so.

\section{Recent reversals in Kenya}

Ms Barimbui emphasised that the outcomes of the intervention demonstrated that teachers' unions had a major role to play in responding to HIV/AIDs in the workplace. Recognising that unions have the capacity to influence behaviour change and prove that HIV is everyone's business, the union initiative reached over 400,000 parents. She said, however, that there were insufficient resources to deal with free primary and free secondary education. The move to universal free primary education has already taken resources away from AIDS programmes. As long as pupilteacher ratios remain in the region of 100:1, and in the absence of adequate statistical data, the implementation of the HIV/AIDS policy would fall by the wayside. The civil unrest in the period December 2007 to March 2008 , fuelled by dissatisfaction with the outcome of the Kenyan elections, triggered a major reversal in the advances made through the KNUT programme. Following the election, there were widespread incidents of rape of children and women, and disruption of medical care and access to ARVs. Much-needed medical services disappeared and there was an increase in school drop-out rates in the areas most affected by the conflict. Sadly, Ms Barimbui concluded, there was a likelihood of new cases of HIV/AIDS which will include teachers and there was also evidence of a growing number of cases of cholera and typhoid.

Ms Barimbui closed by recommending that:

- Governments should work closely with education partners in attempting to eradicate the pandemic;

- More resources should be allocated to the fight against HIV/AIDS;

- A higher level of monitoring and evaluation of the pandemic and its effects should be put in place by the Ministry of Education.

The Chair then invited Dr Miller to make a second presentation to the symposium, entitled 'Estimating the Potential Impact of HIV/AIDS on Teacher Supply and Retention in the Caribbean'. Dr Miller said that the presentation drew on the seminal work of Professor Claire Risley of Imperial College, London, who had developed a mathematical model of the dynamics of assessing teacher numbers based on the impact of HIV/AIDS in the absence of anti-retroviral treatment. He argued that in the absence of data on teachers and the HIV/AIDS pandemic in the Caribbean, it was important to assess the connection between HIV/AIDS and education and 
distinguish between its qualitative and quantitative effects. He noted that for a significant period responsibility for addressing HIV/AIDS was confined to the health sector. However, the education sector had now recognised that it has a key role to play in efforts to control the disease (Risley and Bundy, 2007). The paradox, he suggested, was made even more apparent as education could help stop the spread of HIV/AIDS, but the disease damaged and had the potential to destroy the system delivering this education.

\section{Data from UNAIDS, UNICEF and USAID} suggested that in 2004 there were a total of $1,035,900$ HIV/AIDS orphans in the ten Caribbean countries covered. In Haiti, which is not a Commonwealth member, approximately 610,000 children had been orphaned as a result of the pandemic. Projections were for an increase to 1,087,000 in these ten countries by 2010 .

Addressing the effect of HIV/ AIDS on the quality of education delivery and supply, $\mathrm{Dr}$ Miller proposed that the most crucial effect on the supply of education was the decreased availability of experienced teachers. The impact on teacher productivity manifested itself in absences, loss of energy and motivation (Kelly, 2000). Dr Miller also felt that access to anti-retroviral treatment was a key issue and was critically important for maintaining the productivity of teachers living with HIV/ AIDS.

Dr Miller quoted from Kelly and Bain (2005), who advised that as a consequence of the pandemic, the quality of education delivery might be diluted by a combination of factors, including the loss of trained and experienced teachers, the reduction in teacher productivity through illness and psychological stress, and the loss of management capacity.

Unfortunately, no country in the Caribbean had yet undertaken a comprehensive impact assessment of the effects of HIV/AIDS on the education sector (Risley and Bundy, 2007). These researchers used the Ed-SIDA model to forecast the impact of HIV and AIDS on the supply of teachers in the Caribbean.

Dr Miller said that the focus of his study was a country-by-country analysis of the Caribbean region with the data added together to provide regional projections. He presented projections for the entire Caribbean, the Organisation of Eastern Caribbean States (OECS), Guyana, and Trinidad and Tobago, which illustrated the impact upon individual states. The study relied on the following sources and on the baseline assumption that anti-retroviral treatment would be provided to all teachers who require it up to 2015.

\section{Figure 4: HIV/AIDS and teacher absences and deaths}

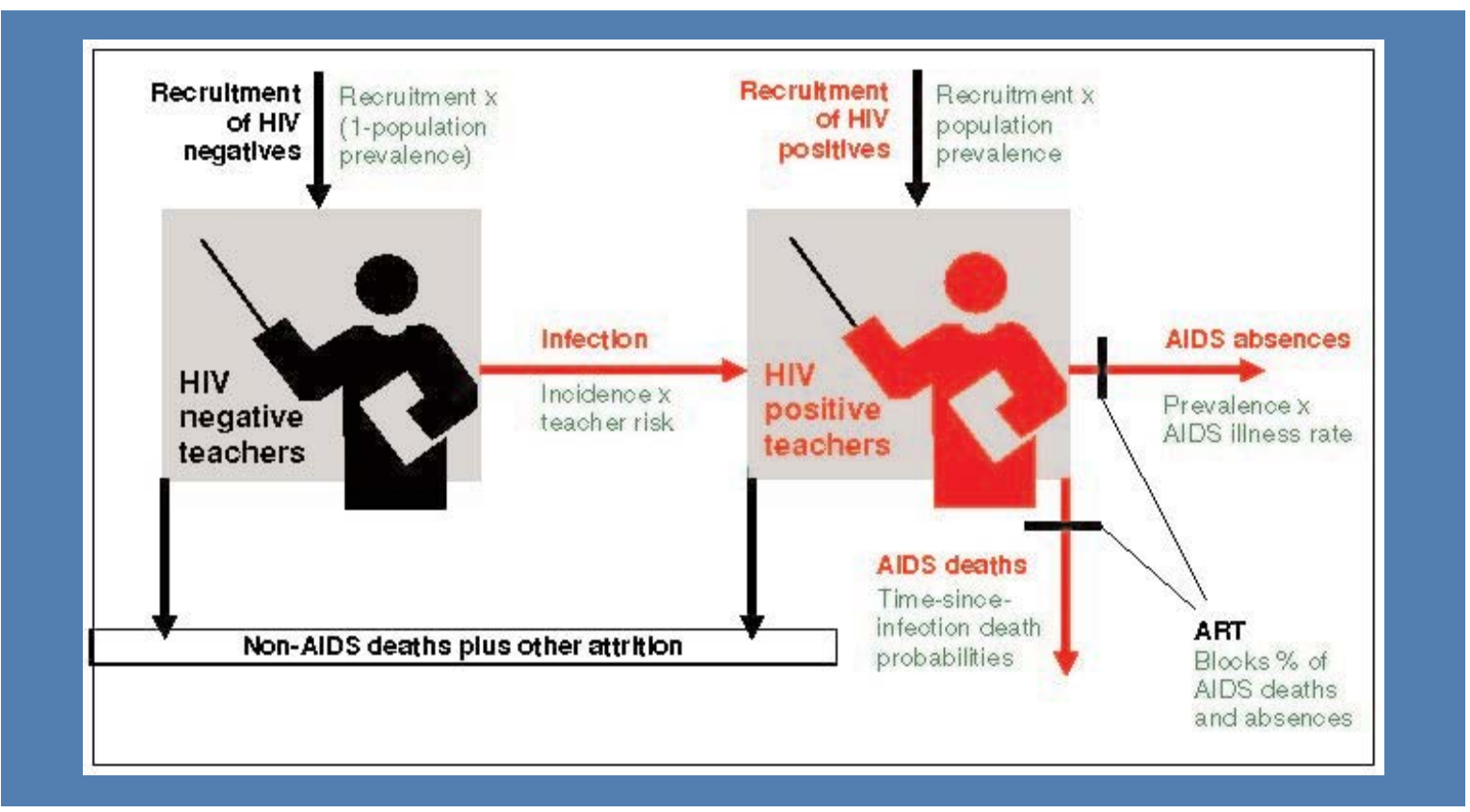


The following factors and sources of information were taken into account in analysing the findings:

- Country-specific HIV prevalence projections based on antenatal clinic surveillance data and scaled to the 2004 estimates made by UNAIDS or the Caribbean Epidemiology Centre;

- Number of teachers, based on data provided by UNESCO Institute of Statistics (UIS);

- Attrition and recruitment data were assumed to be equal across the region;

- Financial data were obtained from Fitzgerald and Gomez (2003) (anti-retroviral medicine costs); Lewin, 2002 (teacher salary and training costs);

- Country reports on social security at http://www.ssa.gov (funeral costs) and Babb (Jamaican teacher training and salary costs).

Using these data in conjunction with the Risley (Imperial College) mathematical formula, the study yielded a number of results.

\section{Table 5: Estimates of the number of teachers who will be HIV-positive or have died from AIDS-related illnesses by 2015}

\begin{tabular}{l|c|c|c|} 
& $\begin{array}{l}\text { Estimated } \\
\text { numbers } \\
\text { of HIV- } \\
\text { positive } \\
\text { teachers } \\
\text { by 2015 }\end{array}$ & $\begin{array}{l}\text { Teacher } \\
\text { AIDS } \\
\text { deaths to } \\
2015\end{array}$ & $\begin{array}{l}\text { AIDS } \\
\text { deaths in } \\
2015 \text { as } \\
\text { a per } \\
\text { centage of } \\
\text { all deaths }\end{array}$ \\
\hline Caribbean & 9,300 & 11,800 & $13 \%$ \\
\hline OECS & 100 & 100 & $5 \%$ \\
\hline Guyana & 200 & 200 & $13 \%$ \\
\hline Trinidad & 300 & 300 & $9 \%$ \\
\hline
\end{tabular}

Note: Data rounded to nearest 100 , assuming a medianprevalence scenario and anti-retroviral treatment given to all teachers needing it (baseline attrition rate from Grenada)

Indications are that teacher turnover in Caribbean schools was fairly low compared to the UNESCO baseline of 3 per cent, which results in a significant AIDS loss in terms of overall attrition. Therefore, the loss of some 12,000 teachers in the Caribbean by 2015 represents a significant impact. HIV/AIDS would have a financial impact on the supply of education in the region.

In conclusion, Dr Miller said that the projections suggested that the number of HIV-positive teachers and teacher deaths from AIDS-related illnesses were likely to increase among Caribbean teachers during the next few years. The life expectancy of HIV-positive teachers would increase, however, if all teachers were given anti-retroviral treatment. Deaths would continue to increase, as teachers who became infected during the initial peak in incidence would die despite treatment. Countries with higher HIV prevalence and larger populations would lose more teachers. Smaller islands might be disproportionately affected by small shocks to the education system.

Dr Miller explained the special challenges faced by small states in educational development, including human resource difficulties in specialist areas resulting in the need for 'multifunctionalism'. He emphasised that even with the best data, the future of the epidemic was difficult to predict, especially at country level (Risley and Bundy, 2007). It should be recognised that the results presented were an indicative analysis based on limited data.

In summary, Dr Miller stressed that on the evidence of this preliminary data, HIV/AIDS would have a significant impact on the supply of education in the Caribbean. While countryspecific analyses were needed to allow for disparities between countries, multi-sectoral strategies should be strengthened to support:

- Prevention of HIV transmission;

- Care and support for those who were infected or affected (including provision of anti-retroviral treatment);

- Managing systemic and institutional impact.

He concluded that whereas at present the education sector's response to HIV/AIDS had concentrated, appropriately, on HIV prevention, it was time to make a comprehensive impact assessment in order to mitigate the negative effects on education delivery in the future. 